\title{
A EMANCIPAÇÃO DAS MULHERES NO MEIO RURAL: AMBIENTE EM QUE O DISCURSO DE GÊNERO AINDA PROCURA SEU ESPAÇO
}

\author{
THE EMANCIPATION OF WOMEN IN RURAL AREAS: ENVIRONMENT IN WHICH \\ GENDER SPEECH IS STILL LOOKS FOR YOUR SPACE
}

\section{LA EMANCIPACIÓN DE LAS MUJERES EN EL ENTORNO RURAL: UN ENTORNO EN EL QUE EL DISCURSO DE GÉNERO AÚN BUSCA SU ESPACIO}

Adriane Medianeira Toaldo

Doutora e Mestre em Direito pela Universidade de Santa Cruz do Sul (UNISC), Santa Cruz do Sul, RS; Especialista em Direito Civil e Processual Civil pelas Faculdades Integradas do Instituto Ritter do Reis, Canoas, RS; E-mail: adrianetoaldo@gmail.com. OrcidID: http://orcid.org,/0000-0002-1321-9859

Resumo: O debate em torno das questões de gênero ainda é recente e está conquistando seu espaço, com maiores restrições no mundo rural em face de ser esta ainda uma sociedade com forte patriarcado. O presente estudo tem como objetivo o debate acerca da emancipação da mulher rural com fulcro nas questões de gênero, propondo seu empoderamento a partir de uma ressignificação de sua condição feminina e de sua percepção formada a partir de um olhar sobre si mesma. Trata-se de uma pesquisa bibliográfica, centrada no método hipótetico dedutivo, que debate o conceito de gênero, a situação da mulher rural e aponta caminhos para sua emancipação. Concluiu-se que, assim como acontece em solo urbano, ainda há muito a ser feito em prol da igualdade de gênero, sem perder a perspectiva de respeito às diferenças. Homens e mulheres, superadas as desigualdades que foram construídas simbolicamente, podem partilhar uma sociedade mais justa e igualitária, bastando, para tanto, que ambos estejam dispostos a mudar e abandonar paradigmas antigos.

Palavras-chave: Gênero. Emancipação feminina. Mulher rural.

Abstract: The debate around gender issues is still recent and is conquering its space, with greater restrictions in the rural world in the face of being still a society with strong patriarchy. The present study aims to debate the emancipation of rural women with a fulcrum in gender issues, proposing their empowerment based on a resignification of their female condition and their perception formed from a look at oneself. This is a bibliographical research, centered on the deductive hippotic method, which discusses the concept of gender, the situation of rural women and points out ways for their emancipation. It was concluded that, as in urban soil, there is still much to be done for gender equality, without losing the perspective of respect for 
differences. Men and women, overcoming the inequalities that have been symbolically constructed, can share a more just and egalitarian society, so that both are willing to change and abandon old paradigms.

Keywords: Gender. Female emancipation. Rural woman.

Resumen: El debate en torno a las cuestiones de género es todavía reciente y está conquistando su espacio, con mayores restricciones en el mundo rural de cara a ser esta todavía una sociedad con fuerte patriarcado. El presente estudio tiene como objetivo debatir sobre la emancipación de las mujeres rurales con un punto de apoyo en cuestiones de género, proponiendo su empoderamiento basado en una resignificación de su condición femenina y su percepción formada a partir de una mirada a sí mismas. Se trata de una investigación bibliográfica, centrada en el método hipotético deductivo, que discute el concepto de género, la situación de las mujeres rurales y señala las formas de su emancipación. Se concluyó que, al igual que en el suelo urbano, aún queda mucho por hacer por la igualdad de género, sin perder la perspectiva del respeto a las diferencias. Hombres y mujeres, superando las desigualdades que se han construido simbólicamente, pueden compartir una sociedad más justa e igualitaria, para que ambos estén dispuestos a cambiar y abandonar viejos paradigmas.

Palabras clave: Género. Emancipación femenina. Mujer rural.

\section{INTRODUÇÃO}

Não faz muito tempo que a palavra gênero entrou no debate a respeito das questões femininas, evidenciando que houve uma longa naturalização de costumes e de divisão dos papéis masculinos e femininos, orientando a conduta de homens e mulheres desde sua fase infantil até a vida adulta. Os estudos em torno deste termo estão ajudando muitas mulheres a encontrar a explicação para uma desigualdade que sentiam, mas não podiam compreender bem suas causas e consequências.

Por acreditarem nas diferenças de gênero, as mulheres, responsáveis pela educação dos filhos na maior parte dos casos, acabavam reproduzindo os valores da cultura patriarcal, ensinando como estes deviam se portar, o que vestir, que brincadeiras eram apropriadas para cada sexo e assim por diante. Por isto, é tão importante que se debata o conceito de gênero, no sentido de romper as amarras e propiciar o empoderamento feminino.

Este artigo propõe uma reflexão a respeito da condição da mulher rural e de sua possibilidade de empoderamento a partir do conceito de gênero, essencial para modificar a relação entre homens e mulheres, propiciando uma igualdade com respeito à diversidade. Entende-se que as mulheres do meio rural, assim como as que vivem em solo urbano, estão na iminência de romper com paradigmas que as aprisionaram durante séculos, tendo como ferramentas estes conceitos revolucionários para sua condição. Com efeito, nenhum dos 
pressupostos desenvolvidos antes dos estudos de gênero possuía este alcance, capaz de fazer a mulher olhar para dentro de si, entender suas expectativas e fazer uma nova leitura de sua vida.

O estudo consiste em uma revisão bibliográfica realizada sob a égide do método hipotético-dedutivo, que faz uma incursão sobre os princípios gerais sobre gênero e os insere na realidade da mulher rural brasileira, notadamente, no que tange à sua participação e empoderamento.

O trabalho consiste em três partes, divididas para melhor compreensão da temática. Em um primeiro momento, descortina-se a ideia de gênero e de como a naturalização das diferenças constituiu uma forma de aprisionamento das mulheres a práticas sociais que minimizavam sua condição e seu potencial.

A segunda parte do trabalho enfoca a atualidade da mulher rural, que com força e determinação, suporta todo o peso da estrutura familiar e as condições sufocantes de um patriarcado que as condena a muitos deveres e impede seus direitos, tornando a sua vida muito desigual em relação aos homens.

Por fim, o terceiro momento do estudo vislumbra o processo de emancipação da mulher, englobando diversas convenções internacionais e a posição da legislação brasileira, afirmando que existem condições para a emancipação do gênero feminino, também, na esfera rural.

\section{SER MULHER... A QUESTÃO DO GÊNERO}

Este primeiro tópico tem como objetivo situar o papel da mulher nos discursos de gênero e apontar caminhos para a emancipação feminina através da desconstrução do discurso masculino predominante sobre ela.

A noção de gênero ainda é nova entre os estudiosos e muito menor ainda na realidade cotidiana de homens e mulheres, principalmente quando se fala em meio rural. Assim, entende-se que, em um primeiro momento, é necessário esclarecer esta questão que permeia o discurso da emancipação feminina.

Uma forte afirmação, a de ser mulher, constitui o primeiro identificador deste debate na procura de uma identidade que entenda o conceito, que evidencie uma postura, uma particularidade em relação ao que é o seu oposto, o homem. A mulher tem necessidade de se afirmar como ser, de se colocar no centro de sua própria vida e de autoconstruir a sua imagem, e não de ficar reproduzindo o retrato que pintaram a seu respeito. Ser mulher, neste sentido, significa pensar seu gênero enquanto produtor de sua própria identidade, ainda que não se possa fazer isto sem correlacionar com o mundo masculino. Mas deve ser a partir de si que a ideia de 
ser mulher necessita florescer. Este é um primeiro passo muito importante em sua ideia de emancipação, pois durante muito tempo a mulher viveu para o outro, sendo necessário transformar esta mulher do outro para mulher em si (TOURAINE, 2011).

É claro que esta não é uma mudança simples e fácil, pois não há como ignorar que já existe uma visão dominante masculina, da qual é preciso se libertar para depois se pensar em uma visão feminina. Esta é uma mudança de consciência que não depende somente das mulheres, mas também dos homens, pois sabe-se que a divisão sexual, que perdura por séculos e está impregnada na cultura, está presente no cotidiano, na ocupação e divisão dos espaços.

Exige, assim, uma mudança de paradigmas na educação de novas gerações, mostrando que a busca da igualdade, ou valorização das diferenças, assim como a construção da desigualdade constitui uma construção histórica que precisa ser desfeita. É necessário desmascarar a naturalidade das relações sociais, que legitimou a diferença entre o masculino e o feminino, amparada em justificativas de caráter biológico, cuja fundamentação não encontra respaldo na atual conjuntura de desenvolvimento social e econômico (BORDIEU, 2007).

Para romper com o estabelecido, é preciso pensar e repensar a questão de gênero ${ }^{1}$, instituída pelo mundo masculino como uma forma de dominação, pois pressupõe a existência de esferas separadas e desvinculadas uma da outra. Assim, o gênero é uma expressão criada para naturalizar uma diferença que é apenas simbólica, mas que não reflete a realidade dos homens e mulheres em seu cotidiano.

Além disso, existem vertentes que creditam o fato da desigualdade de gênero de renda como uma consequência da hierarquia racial experimentada no Brasil (SANTOS, 2009). Assim, há resquícios preconceituosos enraizados no subconsciente da sociedade, resultando em um discurso quase que natural de predominância masculina nas tarefas de cunho técnicoprofissional, independente da área de atuação.

Compreende-se que a maioria dos papéis estabelecidos pela sociedade é transmitida através da família, núcleo estrutural de formação de valores culturais. É a família, em primeira instância, que determina o que vai ser masculino e feminino a partir do nascimento, construindo-se os gêneros durante a fase da infância e da adolescência. Tudo começa pela cor das roupas, tipo de vestimentas, brinquedos adequados para meninas e meninos e até mesmo os

\footnotetext{
${ }^{1}$ A palavra "gênero" começa a ser utilizada nos anos 80 do século XX, pelas feministas americanas e inglesas, para explicar a desigualdade entre homens e mulheres concretizada em discriminação e opressão das mulheres. Nessa época, as investigações sobre a condição social das mulheres já apontavam uma forte desigualdade entre homens e mulheres, que tendia a aumentar conforme a classe social, raça, etnia e outras condições de vida. A desigualdade abarcava a esfera pública e privada. Na primeira, era visível nos salários menores do que o dos homens em serviços iguais e na pequena participação política. Na esfera privada, se evidenciava pela dupla moral sexual e na delegação de papéis domésticos (MPF, 2008).
} 
pequenos detalhes de comportamento. Quando uma menina ganha uma boneca, nela está inscrita a ideia de que está ganhando uma filha para cuidar, papel que lhe está reservado na vida adulta, entre as tantas tarefas do lar. Cada família constitui uma entidade com estruturas próprias nas quais estão presentes regras, ideologias, objetivos e papéis peculiares que formam a "identidade familiar", semelhante à identidade do indivíduo (MARODIN, 1997).

Desta forma, entendendo que a ideia de gênero engendra os significados atribuídos aos diferentes papéis culturais de cada sexo, também sabe-se que é possível romper com esta determinação e naturalização das relações, amparando-se naquelas mulheres que foram capazes de ver formas alternativas e emancipadoras do olhar de gênero, como a francesa Simone de Beauvoir, que mostrou, em seu livro "O segundo sexo", as contradições inerentes ao mundo feminino dependente do masculino e inspirou mudanças a partir da célebre frase "não se nasce mulher, torna-se mulher". A frase reafirma a ideia de que ser mulher ou homem é construída culturalmente e repassada através da educação intergeracional, por intermédio da iniciativa das próprias mulheres, bem como por decorrência de movimentos sociais (PEREIRA, 2004).

É o que acontece quando a mulher deixa de ser apenas a "rainha do lar" e passa a desempenhar diferentes papéis na vida pública e na esfera privada, ampliando suas aspirações para além do casamento e dos filhos, rompendo a dicotomia entre os espaços públicos e privados. É preciso ressaltar a importância de a mulher ocupar, cada vez mais, postos no mercado de trabalho e de ter havido avanços científicos importantes em relação à fecundação, o que a iguala em relação ao homem em suas possibilidades de relação (VAITSMAN, 2001).

Sabe-se que esta realidade está mudando, pois a mulher está gradativamente tomando consciência de suas possibilidades, ingressando cada vez mais no mercado de trabalho e conquistando seu espaço, aprendendo a dividir com os homens as tarefas, tanto das empresas como domésticas. Uma das características mais marcantes da vida das mulheres brasileiras nos últimos 40 (quarenta) anos é a elevação de sua participação no mercado de trabalho (GIORGION, 2013).

Não obstante, o último relatório anual sobre igualdade no mundo, promovido pelo Fórum Econômico Mundial, divulgou que, no ano de 2019, o Brasil se encontrava na 92 posição dentre os 153 países objeto da pesquisa. Segundo o relatório, nosso país apresenta uma das maiores desigualdade de gênero da América Latina, com uma perspectiva média de 59 anos até que as disparidades entre homens e mulheres sejam superadas no território brasileiro (G1, 2019).

Depreende-se, assim, que o caminho está na libertação da rígida separação de gêneros, que consegue ofuscar aquilo que realmente a mulher é em sua condição, não daquilo 
que lhe foi imposto, mas de seu verdadeiro potencial como pessoa, muito além dos estereótipos. Esta liberdade também deve ser vista em relação a mulher do campo. Por isto, na sequência, se busca analisar o espaço da mulher no meio rural e a sua condição feminina neste âmbito.

\section{A CONDIÇÃO DA MULHER RURAL: MAIS DEVERES DO QUE DIREITOS}

Neste segundo tópico do trabalho, procura-se situar a mulher no meio rural a partir de uma perspectiva libertadora de gênero e da compreensão dos fatores que fazem com que a sociedade, por diferentes razões culturais, sociais, econômicas e políticas, atribui diferentes papéis a ambos os sexos.

Primeiramente, considera-se importante ressignificar a ideia de espaço rural, entendendo, que na contemporaneidade, este já não se define exclusivamente pela atividade agrícola, mas enseja um conjunto de atividades correlacionadas, com novos arranjos produtivos que estão desmistificando a imagem de agricultor de tempo integral, visto que estas atividades estão servindo como uma alternativa ao êxodo rural, ao desemprego urbano e ao próprio agronegócio. Além disso, verifica-se um retorno ao campo, em que pessoas procuram por mais qualidade de vida, mudança de vida e espaços de lazer, longe da agitação dos grandes centros.

Entende-se que o espaço rural está passando por um grande processo de ressignificação, deixando de ser um subproduto dependente do meio urbano, construindo alternativas para seu próprio desenvolvimento, o que, inevitavelmente, está alterando sua composição familiar e suscitando novas questões de organização social.

Desta forma, o meio rural está se reinventando, propiciando as condições para que as famílias tenham maior qualidade de vida, oportunidades de crescimento, deixando de se tornar um lugar de sofrimento para se transformar em um espaço comunitário de progresso. Muitos agricultores, inclusive, estão apostando na produção orgânica, resultado de sua capacitação através de políticas públicas, passando a estabelecer uma nova relação de simbiose com o meio ambiente, entendendo as vantagens do desenvolvimento econômico e social combinado com a preservação do meio ambiente ${ }^{2}$ (KARAM, 2004).

Esta revalorização do mundo rural também gerou um resgate dos costumes que tinham sido esquecidos ou até mesmo depreciados, como se fosse "coisa de colono". Assim,

\footnotetext{
${ }^{2}$ Muito do que diz sobre o mundo rural decorre de uma concepção que o subordina ao urbano, como locus privilegiado de realização do que é moderno e do que é progresso, ao contrário do que é tradicional e atrasado, o mundo rural. No entanto, mesmo aqueles que consideram o urbano moderno ainda continuam se surpreendendo com a capacidade de transformação e de mudanças que ocorrem no mundo rural (KARAM, 2004).
} 
assiste-se a um ressurgir dos costumes, da culinária, das expressões artísticas, ou seja, de tudo que se produz culturalmente nesse meio. Como foi dito antes, o que se produz no meio rural virou atração para o mundo urbano, através do turismo rural, aumentando a renda das famílias e gerando maior conforto e qualidade de vida (CARNEIRO, 1988). É uma nova ruralidade que está aflorando, ressignificada em sua expressão e ocupação do espaço, havendo o reconhecimento de que houve modificação tanto na sua relação com o urbano como nas suas relações internas e específicas (KARAM, 2004).

A ideia de ruralidade como um mundo autônomo e complexo ainda é nova, mas está gradativamente conquistando espaço entre os produtores rurais, que passam a ver novas possibilidades em um mundo que está se transformando, integrando-se a uma lógica de interrelação com o mundo inteiro. A globalização também chegou ao campo e com ela um mundo novo de atrações e de diversidades.

Entendidas as transformações pelas quais passa o meio rural, cabe agora entender qual o papel da mulher neste contexto, pois esta ocupa e sempre ocupou funções consideradas chaves para a segurança alimentar e organizacional, desempenhando um papel estratégico na manutenção e permanência da ruralidade. A mulher é responsável direta pela produção de alimentos, pela organização da casa, pela educação dos filhos, pela modernização e elevação do nível cultural e pela permanência das tradições. E são justamente elas que estão procurando novos espaços de atuação, passando a participar com mais intensidade e frequência das decisões de sua comunidade, ainda que estejam vinculadas com muita força às tarefas domiciliares (SANZ, 2013).

Porém, mesmo quando a mulher executa atividades iguais aos dos homens, estas não são valorizadas, aparecendo apenas como uma ajuda ao trabalho masculino, sobretudo em relação aos salários pagos a ela, flagrantemente discriminatórios. A posição subordinada da mulher aparece de forma ideologizada, pois é bastante invisível e há pouco controle feminino sobre a produção. As atividades que ela executa não a deixam em evidência, ficando em segundo plano, destinando-se à limpeza da terra e colheita, seleção e embalagem dos produtos, processamento dos produtos agrícolas, cuidado com animais e trabalhos na horta. Além disso, são responsáveis por todo o trabalho doméstico, esfera na qual possui autonomia e poder, tomando decisões sobre o preparo de alimentos, cuidado com a roupa, orientação e educação dos filhos e utilização dos recursos de uso doméstico (BRUMER, 2004).

O que não se percebe é que, desde pequenas, as pessoas foram educadas para ter comportamentos diferentes conforme o seu gênero. Esta construção histórica destinou às mulheres um conjunto de tarefas que, supostamente, se enquadram melhor com seu jeito de ser. 
Esta desigualdade de gênero, que atribui às mulheres (principalmente às mais jovens uma posição subordinada na estrutura familiar - cuja evidência acontece nas atividades na esfera da produção e de reprodução, de poder e de acesso à propriedade da terra - explica porque essas têm menores perspectivas profissionais e motivação para permanecer no meio rural dos que os homens. No entanto, deve-se supor que este processo, embora ainda dominante, não ocorra em todos os lugares, porque a mulher tem sido a protagonista, em muitos casos, de inovações dentro do processo produtivo (KARAM, 2004, p. 304).

A divisão do trabalho que se estabelece entre homens e mulheres rurais pode ser explicada em dois aspectos. O primeiro é a união de todos os membros da família na produção e consumo de bens, pois há um esforço coletivo para o desempenho das atividades, que não são poucas, envolvendo todo os integrantes. Desde pequeninas, as crianças se inserem no trabalho rural, fazendo aquilo que sua condição física lhes permite. O segundo ponto é a existência de uma sociedade tipicamente paternalista, na qual o personagem masculino ainda é considerado o provedor da família, pois parece depender dele a parte do trabalho que gera a maior parte da renda familiar, como se as demais tarefas tivessem uma importância secundária. $\mathrm{Na}$ verdade, tanto o trabalho do homem como o da mulher se complementam, auxiliado pelas crianças e adolescentes. O problema é que, em muitos casos, o trabalho da mulher não gera renda direta e isto dificulta a noção de valor atribuído ao mesmo (BRUMER, 2004).

Entende-se que o maior obstáculo à emancipação feminina no campo decorre da falta de oportunidades que as mulheres possuem de ter renda própria e individualizada, bem como acesso ao conhecimento, o que permitiria que as mesmas pudessem romper com o ciclo de dominação patriarcal. Sem estes instrumentos, a educação que elas podem prover a seus filhos não poderá fugir de modelos arcaicos.

Além de não ser reconhecida pelo trabalho que realiza, a mulher também não leva créditos pelos avanços que propicia no meio rural, pois estudos comprovam que ela tem sido pioneira no desenvolvimento de novas técnicas de produção, no sentido de se mudar o sistema de plantio tradicional para uma agricultura orgânica, reordenando o espaço familiar e construindo uma nova unidade que se estende para a comunidade. Em vários estabelecimentos comerciais, ela é responsável pela unidade de produção, acontecendo também casos de produção cooperada, somando forças para executar o planejamento da produção, a preparação da terra e o plantio até a colheita, a comercialização e a divisão dos lucros do trabalho (KARAM, 2004).

Este empoderamento no meio familiar, que ocorre nas situações em que a mulher se torna mais ativa do sistema de produção e comercialização, faz com que ela tenha maior 
inserção na comunidade, pois em várias localidades rurais tem havido a organização coletiva para obter maior resultado produtivo. Quando ocorre esta organização coletiva da produção, da mesma forma que as pessoas se organizam em sindicatos, criam-se as condições propícias para que outros assuntos e questionamentos surjam, principalmente aqueles que dizem respeito à estrutura familiar e à condição da mulher no meio rural, visto que, pelo fato de muitas atividades não gerarem renda, não serem valorizadas (BRUMER, 2004).

O protagonismo feminino tem sido uma constante no meio rural, através do intercâmbio e da criação de cooperativas de produção, situação em que as mulheres deixam de ser dependentes das decisões masculinas para debater seus negócios e suas próprias questões, o que contribui sobremaneira para um processo de emancipação, que é facilitado pelo fato de que elas agora são geradores de renda.

A condição da mulher rural tem gerado debates em nível mundial, capitaneados pela Organização das Nações Unidas, que defende a ideia de inserir as mulheres em correntes de desenvolvimento para diminuir a pobreza feminina, acrescentando-se o fato de que a sua aproximação com a agricultura e o manejo dos recursos naturais é de vital importância para os direitos humanos e ecológicos no mundo de hoje (FIÚZA, 2001). Desta forma, o mundo rural se reinventa com novas perspectivas de gênero, atribuindo à mulher do campo possibilidade de se emancipar em suas tarefas. No entanto, o processo cultural é muito lento e as mudanças acontecem gradativamente.

Como se observa a mulher rural é responsável por inúmeras ações do campo, cuja emancipação ainda é incipiente. Por conta disso, na sequência, se analisa como como as questões de gênero estão influenciando no mundo rural e qual a participação das mulheres nesse processo

\section{O MUNDO RURAL E AS QUESTÕES DE GÊNERO: UM CAMINHO LENTO RUMO À EMANCIPAÇÃO FEMININA}

Neste tópico serão analisados os movimentos de emancipação da mulher no Brasil, notadamente no campo, no qual elas se tornaram protagonistas de lutas por melhorias em sua condição de vida. 
O movimento das mulheres é comumente denominado de movimento feminista ${ }^{3} \mathrm{e}$ faz parte de um conjunto de ações chamados de novos movimentos sociais, que englobam mobilizações das chamadas minorias (mulheres, negros, homossexuais), assim denominadas não por serem minoria na sociedade, mas por terem seus direitos diminuídos e por serem considerados grupos com pouca expressão social. Tem sido comum, além da organização de movimentos de mulheres, a constituição de setores, dentro dos movimentos sociais, para atender pautas específicas do mundo feminino. Nos governos, secretarias especiais para formular políticas públicas para mulheres têm sido criadas, com a intenção de garantir direitos e evitar discriminações e violência. Todas estas mudanças na forma como as mulheres são vistas e como elas mesmas se veem são consequência direta do movimento feminista.

Entende-se o feminismo como um movimento que conseguiu alterar de maneira profunda a concepção dominante masculina existente no mundo ocidental, em diversos setores do pensamento e da cultura, notadamente em relação aos direitos das mulheres. Uma pessoa que nasceu no final do século passado e que tenha em torno de vinte anos de idade, não é capaz de imaginar que até há bem pouco tempo atrás, as mulheres não tinham uma série de direitos, como os de firmar contrato, de ter propriedade, de votar, de autonomia e de integridade de seu corpo, bem como de assuntos reprodutivos, proteção contra a violência doméstica, assédio sexual, estupro, como também diversos direitos trabalhistas básicos, como licença maternidade, além de salários iguais.

É importante pensar que o conjunto de direitos conquistados pelas mulheres derivam de várias décadas de luta e de conscientização. E mais importante ainda saber que, embora diversos direitos tenham sido alcançados no plano da lei, eles ainda não se efetivaram socialmente, com é o caso das diferenças salariais, pois os homens, na maior parte do mundo, ainda que exerçam atividades iguais, recebem mais que as mulheres nos mesmos cargos.

Costuma-se dividir o movimento das mulheres em três fases. A primeira delas teria ocorrido entre os séculos XIX e XX, mais centradas em questões políticas, como é o direito ao voto (PINTO, 2003). Um segundo momento de luta das mulheres ocorreu a partir dos anos 1970, em que as mulheres participaram ativamente da luta contra a ditadura, e também como resultado do processo de modernização que implicou em uma maior incorporação das mulheres no mercado de trabalho. A esta luta se incorporaram outras lutas de minoria, como a dos negros

\footnotetext{
3 "O feminismo é um movimento que objetiva a libertação da mulher de dogmas impostos por sociedades patriarcais. Esse movimento, dos Estados Unidos, na década de 60, desenvolveu-se rapidamente por todos os países industrializados. Como movimento, auxiliou na conscientização de uma minoria que é majoritária quantitativamente.” (SÉGUIN; SANTOS; RODRIGUES. 2005, p. 81).
} 
e homossexuais. As mulheres vinculadas às associações de moradores começaram a enfocar temas ligados a especificidades de gênero, tais como creches e trabalho doméstico, espalhandose por todas as grandes cidades do Brasil, incorporando novas bandeiras, como direitos reprodutivos, combate à violência e por maior liberdade sexual (COSTA, 2009).

A partir de 1980, uma terceira fase do movimento feminista ocorre no Brasil, com a criação dos Conselhos dos Direitos da Mulher, nos Estados e cidades e, também, com o Conselho Nacional dos Direitos da Mulher, que se tornaram novos interlocutores na relação com os movimentos. Havia, segundo o autor, duas posições dentro do movimento que polarizavam as discussões: ocupar os novos espaços governamentais ou permanecer na exclusividade dos movimentos como espaços feministas (LOBO, 1987).

O ano de 1988 marcou uma reviravolta para as mulheres em termos de legislação, pois foi proclamada a Constituição da República Federativa do Brasil, com ênfase na dignidade humana e na igualdade o que, juridicamente, acabava com as diferenças de gênero. Porém, deve-se entender os dispositivos legais que dizem respeito às questões femininas presentes na Constituição não como uma dádiva ou oferecimento dos congressistas, mas sim como resultado da luta feminista descrita anteriormente, que culminou com a elaboração da "Carta das Mulheres Brasileiras aos Constituintes", tendo como resultado à incorporação dessas reivindicações no texto constitucional de 1988 (PIOVESAN, 2011, p. 60-61).

Os direitos conquistados nesta seara incluem a igualdade entre homens e mulheres (art. $\left.5^{\circ}, \mathrm{I}\right)$, a união estável como entidade familiar (art. 226, $\S 3^{\circ}$ ), a proibição da discriminação no mercado de trabalho (art. $7^{\circ}, \mathrm{XXX}$ ), o dever do Estado de coibir a violência no âmbito das relações familiares (art. 226, $\S 8^{\circ}$ ). Também cabe assinalar o surgimento da Lei Maria da Penha (Lei $\left.\mathrm{n}^{\circ} 11.340 / 06\right)$, instrumento para coibir a violência doméstica e familiar contra a mulher, e a Lei $\mathrm{n}^{\circ} 10.224$, de 15 de maio de 2001, que dispõe sobre o crime de assédio sexual. No âmbito eleitoral, merece ser citada a Lei ${ }^{0}$ 9.504, de 30 de setembro de 1997, que estabelece normas para as eleições, dispondo que cada partido ou coligação deverá reservar o mínimo de trinta por cento e o máximo de setenta por cento para candidaturas de cada sexo (PIOVESAN, 2011, p. $62)$.

O movimento feminista tem exercido papel muito importante na luta pela igualdade de direitos entre homens e mulheres, não apenas no campo nacional, mas também no plano internacional. No âmbito internacional, merece destaque a Convenção sobre a Eliminação da Discriminação contra a Mulher de 1979; a Declaração e o Programa de Ação da Conferência Mundial de Direitos Humanos de Viena de 1933; o Plano de Ação da Conferência sobre População e Desenvolvimento do Cairo de 1944; a Convenção Interamericana para Prevenir, 
Punir e Erradicar a Violência contra a Mulher de 1994 e a Declaração e a Plataforma de Ação da Conferência Mundial sobre a Mulher de Pequim de 1995. Em decorrência desse significativo número de tratados e convenções internacionais, o movimento feminista passou a exigir do governo brasileiro a sua implementação (PITANGUY; MIRANDA, 2006, p. 29).

Em sede de direito internacional, a Declaração de Direitos Humanos de Viena de 1933, traz, em seu artigo 18, verdadeira declaração aos direitos humanos das mulheres e das meninas, "não somente de igualdade, mas ao mesmo tempo de forçosa proteção e combate às violações à dignidade da mulher" (DIAS; COSTA, 2013, p. 76). A Convenção sobre a Eliminação de todas as formas de Discriminação contra a Mulher, realizada em 1979, foi ratificada pelo Brasil em 1984, sendo resultado, também, de ampla reivindicação do movimento feminista, a partir da primeira Conferência Mundial sobre a Mulher, realizada no México, em 1975 (PIOVESAN, 2011, p. 65).

A força do movimento feminista fez com que os governos passassem a respaldar suas conquistas e direitos, estabelecendo um conjunto de leis protetivas e de combate à discriminação. Cita-se, modernamente, como exemplo, a Lei Maria da Penha (Lei ${ }^{\circ}$ 11.340/2006), que deu status de crime à violência doméstica, criando mecanismos de proteção e cuidado às vítimas e punição e distanciamento aos agressores. Além disso, recentemente, em 2015, foi editada a Lei do Feminicídio (Lei $\mathrm{n}^{\mathrm{o}}$ 13.104/2015), que prescreve o assassinato das mulheres pela sua condição e menosprezo. Atualmente, as bandeiras principais do movimento feminista dizem respeito ao combate à violência e à discriminação, principalmente no ambiente de trabalho (pela via do assédio moral e sexual), igualdade salarial, legalização do aborto e na luta pela maior representatividade política.

O movimento das mulheres no campo é um acontecimento recente, que remonta ao período da abertura democrática da década de 1980 e da consolidação do movimento feminista no Brasil. Nas Comunidades Eclesiais de Base era comum haver a liderança das mulheres, que passaram, a partir daí, a ter um papel mais visível na estrutura das relações sociais, pois estas passaram a se tornar líderes destes movimentos (DEERE, 2004).

Aos poucos estas mulheres foram se organizando e conquistando seu espaço, formando os núcleos estaduais do Movimento das Mulheres Trabalhadoras Rurais (MMTR), que eram formados por núcleos municipais e que se reuniam periodicamente para debater sua pauta de reivindicações, a partir de dois temas principais: a necessidade de aumentar a participação das mulheres nos sindicatos e a reivindicação pela reforma agrária. Como se verifica, a luta das mulheres rurais pela sua emancipação não está desvinculada de sua luta pela emancipação da classe trabalhadora rural como um todo, que se concretizaria na distribuição 
de terras através da reforma agrária. Porém, este tom específico de sua luta, que fortalece o movimento dos trabalhadores rurais como um todo, também pontua que a mulher quer se tornar proprietária da terra para conseguir a sua emancipação (DEERE, 2004).

Em 1986 ocorreu o primeiro encontro nacional de mulheres rurais autônomas, cujo objetivo era criar a primeira organização nacional de mulheres trabalhadoras, para se constituir como espaço para lidar com as questões de gênero e com os interesses das mulheres (DEERE, 2004). Embora muitas dessas mulheres tivessem conquistado espaços de liderança nos sindicatos rurais, havia uma frustração quando as reivindicações específicas de gênero eram consideradas irrelevantes ou menos significantes que as reivindicações de classe ou econômicas que motivavam essas organizações. No próprio Movimento Sem Terra (MST), a participação das mulheres tem sido muito visível e estima-se que estas constituam de um terço a metade das participantes, estando, em muitos casos, na linha de frente nos confrontos com a polícia, além de ocupar papéis determinantes na organização das ocupações. No entanto, sempre houve um contraste entre o número de mulheres que participavam e o número de líderes destas organizações, o que sugere a necessidade de uma organização independente.

Outras formas de organização foram os clubes de mães e grupos de mulheres trabalhadoras, que denunciavam a ausência e precariedade dos serviços coletivos municipais e que resultaram em abaixo-assinados, manifestações e encontros municipais, estaduais e municipais. As lutas das mulheres englobam tanto as lutas pela terra quanto a manutenção do seu modo de vida e do acesso ao mundo natural (BONI, 2004).

Entende-se que as questões de gênero constituem uma necessidade à parte na luta por melhores condições de acesso à terra, pois a desigualdade que impera entre as classes sociais, detentoras ou não dos meios de produção rural, se estende e se reproduz na desigualdade existente entre homens e mulheres, o que também consiste em um fato impeditivo para o crescimento da sua luta. Quando homens e mulheres perceberam que a emancipação das mulheres, seja no meio rural ou no meio urbano, contribui para a emancipação da comunidade como um todo. $\mathrm{O}$ crescimento dos direitos das mulheres tem acontecido por duas razões distintas, envolvendo argumentos de natureza produtivista e de empoderamento (DEERE, 2004).

$\mathrm{O}$ argumento produtivista refere-se ao reconhecimento de que o direito das mulheres à terra está associado com o aumento do bem-estar destas e de seus filhos, bem como da comunidade e da sociedade. Por sua vez, o argumento do empoderamento reconhece que os direitos das mulheres à terra são decisivos para aumentar seu poder de barganha dentro da 
família e da comunidade, reduzindo ou acabando com a insubordinação aos homens em busca de uma igualdade.

A mudança dos hábitos não depende apenas das mulheres, uma vez que elas vão incorporar outros papéis, como mãe, esposa e trabalhadora, sendo necessária uma reordenação das tarefas rotineiras, como maior participação dos maridos e filhos, para que a mulher possa assumir seu lugar no sindicato. E esta mudança não é tão simples assim, na medida em que a mulher foi educada para aceitar o que os homens decidem. Assim, para uma dirigente sindical, a igualdade na família consiste em uma pré-condição para a igualdade na luta sindical. No entanto, nem sempre isso é possível e os espaços para a participação da mulher não se constituem em espaços femininos de ser, mas sim sob a lógica masculina. A ideia de que a mulher possa participar de uma maneira mais feminina e, portanto, mais solidária, ainda é um desafio a ser alcançado (BONI, 2004).

Sabe-se que uma longa luta das mulheres e também de homens emancipados ainda está por vir na construção de relações mais igualitárias, para que as próximas gerações sejam educadas a partir de outros paradigmas. A seguir, apresentam-se as conclusões do estudo.

\section{CONSIDERAÇÕES FINAIS}

A história da humanidade sempre se fez com a participação das mulheres, estivessem elas na condição de protagonistas ou em segundo plano, como aconteceu na maioria dos casos, em que sociedades paternalistas atribuíram aos homens papéis de comando e dominação, sob justificativas construídas simbolicamente. Porém, há diversos relatos de mulheres que desobedeceram muitos dos ditames impostos pela sociedade e tomaram seu lugar à frente dos acontecimentos, mostrando que é possível unir inteligência com sensibilidade para resolver as questões de outra maneira.

Atualmente, em pleno século XXI, por mais paradoxal que possa ser e apesar dos inúmeros avanços e conquistas do movimento feminista, ainda persistem muito dogmas e pensamentos atrasados que perduram relações de dominação, principalmente em lugares onde as questões culturais ainda não evoluíram de forma mais avançada.

Se a mulher urbana enfrenta muitas dificuldades no seu longo processo de emancipação, o que se dizer da mulher rural. Não faz muito tempo que a mulher rural brasileira conseguiu efetivar alguns dos direitos mais básicos, como o de ser reconhecida como trabalhadora rural e ter acesso à previdência social. Isso mostra que ainda há um longo caminho a percorrer no sentido de inseri-la como cidadã no Estado Democrático de Direito. Nesse 
sentido, diversas são as necessidades particulares, sociais, jurídicas e políticas a serem efetivadas.

Do ponto de vista pessoal, é necessário que estas mulheres se empoderem, passando a se ver como pessoas portadoras de direitos dentro da sociedade e da família. Muitas não consideram as suas atividades domésticas como trabalho, na medida em que estas não geram renda específica. É preciso que as mesmas entendam que foram submetidas a uma estrutura familiar patriarcal que as subjuga e as impede de se emancipar. Quando as mulheres desenvolvem atividades que geram renda ou quando são atingidas por políticas públicas de gênero elas passam a ver o mundo de uma outra maneira, atingindo outros horizontes e passando a visualizar novas perspectivas.

É necessário que as mulheres percebam e lutem pela sua condição feminina, pela emancipação do gênero, como pré-condição para efetivação da igualdade no campo. Porém, é preciso também haver uma colaboração dos homens para que esta emancipação feminina se torne mais fácil e rápida. Assim como no meio urbano já existem novos homens que compartilham com a mulher as atividades domésticas e ajudam a criar os filhos, possibilitando que estas possam desenvolver suas atividades profissionais, no campo esta ideia pode fazer com que elas dediquem mais tempo às atividades que geram renda ou desenvolver atividades de formação, de criação de grupos e de movimentos em prol de sua emancipação. Sabe-se que muitas das conquistas da mulher rural foram resultados da sua organização em movimentos próprios ou de participação nos movimentos sociais mais gerais.

Assim, entende-se que uma nova postura do homem rural é pré-condição para o empoderamento feminino. Além disso, a sociedade rural precisa acompanhar esta evolução, compreendendo que o modelo de família patriarcal já não é o único possível, aceitando novas formas de configuração familiar em que a mulher não esteja atrelada ao marido. Felizmente, os governos já estão reconhecendo esta realidade e propiciando o acesso à terra para mulheres chefes de família. Ao reconhecer o papel da mulher como fomentadora de negócios agrícolas e como geradora de renda, o poder público incentiva a mulher a tornar-se independente.

Todos estes elementos citados aqui podem mudar a vida das mulheres rurais, empoderando-as para que assumam seu lugar na sociedade, construindo, junto com homens, uma sociedade mais fraterna e mais justa, eliminando-se as desigualdades sociais e, naturalmente, as de gênero. 


\section{REFERÊNCIAS}

BONI, V. Poder e igualdade: as relações de gênero entre sindicalistas rurais de Chapecó, Santa Catarina. Estudos feministas, Florianópolis, v. 12, n. 1, p. 289-302, jan./abr. 2004.

BORDIEU, P. A dominação masculina. Tradução Maria Helena Kühner. 5. ed. Rio de Janeiro: Bertrand Brasil, 2007.

BRUMER, A. Gênero e agricultura: a situação da mulher na agricultura do Rio Grande do Sul. Estudos feministas, Florianópolis, v. 12, n. 1, p. 205-227, jan./abr.

2004.

CARNEIRO, M. J. Ruralidade: novas identidades em construção. Estudos, sociedade e agricultura, n. 11, p. 53-75, 1988.

COLLING, A. A construção histórica do feminino e do masculino. In: STREY, M. N.; CABEDA, S. T. L.; PREHN, D. R. Gênero e cultura: questões contemporâneas. Porto Alegre: EDIPUCRS, 2004. p. 13-38.

CORNELL, D.; THURSCHWELL, A. Feminismo, negatividade, intersubjetividade. In: CORNELL, D.; BENHABIB, S. Feminismo como crítica da modernidade: releitura dos pensadores contemporâneos do ponto de vista da mulher. Tradução de Nathanael da Costa Caixeiro. Rio de Janeiro: Rosa dos Tempos, 1987.

COSTA, A. A. A. O movimento feminista no Brasil: dinâmica de uma intervenção política. In.: PISCITELLI, A.; MELO, H. P.; MALUF, S. W.; PUGA, V. L. Olhares feministas. Brasília: Ministério da Educação: UNESCO, 2009. p. 51-81.

DEERE, C. D. Os direitos da mulher à terra e os movimentos sociais rurais na reforma agrária brasileira. Estudos Feministas, Florianópolis, v. 12, n. 1, p. 175-204, jan./abr. 2004.

DIAS, F. V.; COSTA, M. M. M. Sistema punitivo e gênero: uma abordagem alternativa a partir dos direitos humanos. Rio de Janeiro: Lúmen Juris, 2013.

FIÚZA, A. L. C. Mulheres nas políticas de desenvolvimento sustentável. In: BRUSCHINI, C.; PINTO, C. R. Tempos e lugares. São Paulo: FCC: ed. 34. 2001.

G1.globo. Desiguldade de gênero no trabalho só acabará daqui a 257 anos, aponta Fórum Econômico Mundial. Disponível em: https://g1.globo.com/economia/noticia/2019/12/17/desigualdade-de-genero-no-trabalho-soacabara-daqui-a-257-anos-aponta-forum-economico-mundial.ghtml. Acesso em: 24 fev. 2021.

GIORGION, Mariana. O conceito de Trabalho decente da OIT e a percepção das mulheres brasileiras. Novas perspectivas de gênero no século XXI. Rio de Janeiro. Fundação Konrad Adenauer, 2013.

KARAM, K. F. A mulher na agricultura orgânica e em novas ruralidades. Estudos feministas, Florianópolis, v. 12, n. 1, p. 303-320, jan. abr. 2004. 
LOBO, E. S. Mulheres, feminismo e novas práticas socais. Revista de Ciências sociais, Porto Alegre, v. 1, n. 2, 1987.

MARODIN, M. As relações entre o homem e a mulher na atualidade. In: STREY, M. N. (Org.). Mulher, estudos de gênero. São Leopoldo: UNISINOS, 1997. p. 9-18.

MPF. Dicionário de Direitos Humanos da ESMPU. O que é gênero. Disponível em: http://pfdc.pgr.mpf.mp.br/pfdc/informacao-e-comunicacao/eventos/mulher/dia-damulher/verbet\#: :text $=\mathrm{O} \% 20$ conceito $\% 20 \mathrm{de} \% 20 \mathrm{~g} \% \mathrm{C} 3 \%$ AAnero $\% 20$ segue,identidade $\% 20$ su bjetiva\%20nem\%20sempre\%20coincidem. Acesso em: 25 fev. 2021.

PEREIRA, V. L. Gênero: dilemas de um conceito. In: STREY, M. N.; CABEDA, S. T. L.; PREHN, D. R. Gênero e cultura: questões contemporâneas. Porto Alegre: EDIPUCRS, 2004. p. 173-198.

PINTO, C. R. J. Uma história do feminismo no Brasil. São Paulo: Fundação Perseu Abramo, 2003

PIOVESAN, F. Direitos humanos, civis e políticos: a conquista da cidadania feminina. In.: BARSTED, L. L.; PITANGUY, J. (Orgs.). O progresso das mulheres no Brasil: 2003-2010. Rio de Janeiro: CEPIA: Brasília: ONU Mulheres, 2011. p. 58-88.

PITANGUY, J.; MIRANDA, D. As mulheres e os direitos humanos. In: UNIFEM. O progresso das mulheres do Brasil. Brasília: Cepia/Ford Foundation, 2006. p. 14-31.

SANTOS, José Alcides Figueiredo. A interação estrutural entre a desigualdade de raça e de gênero no Brasil. Revista Brasileira de Ciências Sociais. Rio de Janeiro, v. 24, n. 70, 2009.

SANZ, B. G. La mujer rural en los processos de desarrollo de los pueblos. Revista del Ministerio de Trabajo y Asuntos Sociales, p. 107-120, 2013.

SÉGUIN, E.; SANTOS, M. C.; RODRIGUES, C. C. S. Mulher vista em três fases. Rio de Janeiro: Letra Legal, 2005.

TOURAINE, A. O mundo das mulheres. Tradução de Francisco Morás. 3. ed. Petrópolis, RJ: Vozes, 2011.

VAITSMAN, J. Gênero, identidade, casamento e família na sociedade contemporânea. In: MURARO, R. M.; PUPPIN, A. B. (Org.). Mulher, gênero e sociedade. Rio de Janeiro: Relume Dumará, 2001. p. 13-20.

Data de recebimento: 13.01.2021

Data de aprovação: 15.03.2021 